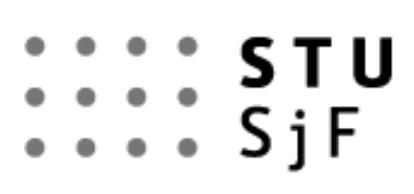

DE GRUYTER OPEN

\section{Journal of MECHANICAL ENGINEERING \\ - Strojnícky časopis}

VOLUME 66, NO 1, 2016

pp. $53-64$

DOI:10.1515/scjme-2016-0011

\title{
COMPARISON OF THE VISCOUS LIQUIDS SPRAYING BY THE OIG AND THE OIL CONFIGURATIONS OF AN EFFERVESCENT ATOMIZER AT LOW INLET PRESSURES
}

\author{
MLKVIK Marek ${ }^{1}$, OLŠIAK Róbert ${ }^{1}$, SMOLAR Marek ${ }^{1}$ \\ ${ }^{1}$ Slovak University of Technology in Bratislava, Faculty of Mechanical Engineering, Institute of of Energy \\ Machinery, Nám. Slobody 17, 81231 Bratislava, Slovakia, e-mail:marek.mlkvik@stuba.sk
}

\begin{abstract}
In this work we studied the influence of the fluid injection configuration (OIG: outside-in-gas, OIL: outside-in-liquid) on the internal flows and external sprays parameters. We sprayed the viscous aqueous maltodextrin solutions $(\mu=60 \mathrm{mPa} \cdot \mathrm{s})$ at a constant inlet pressure of the gas and the gas to the liquid mass flow ratio (GLR) within the range 2.5 to $20 \%$. We found that the fluids injection has a crucial influence on the internal flows. The internal flows patterns for the OIG atomizer were the slug flows, the internal flow of the OIL device was annular which led to the significant improvement of the spray quality: Smaller droplets, faster atomization, fewer pulsations.
\end{abstract}

Keywords: effervescent atomizer, OIL atomizer, OIL atomizer, flow visualization, CFD, droplet sizing, sprays

\section{Introduction}

The liquid atomization by internal-mixing twin-fluid nozzles is widely used as an alternative to the other spraying techniques. These atomizers are specific by using a pressurized gas to enhance the liquid breakup. In contrast with their external-mixing counterparts is the atomizing gas introduced into the bulk liquid at some point upstream the discharge orifice. This gas is injected at low velocity and, therefore, is not intended to impart kinetic energy of the flow. The gas is used to improve primary breakup by its expansion when leaving the discharge orifice. The advantage of this concept is proven by many industrial applications - combustion [5], food processing industry [10], the pharmaceutical industry and many others .

The spraying by above-mentioned devices is a complex process which can be divided into the several stages: The injection of fluids into a mixing chamber, their mixing and formation of internal flow, the liquid discharge, the primary and the secondary breakup [6].

From all the atomization stages, the liquid mixing and the internal flow formation are the processes of an outstanding importance for the final spray quality [4], [7], [11]. The internal flow pattern can be estimated by the analytical methods - the flow regime maps. In the past decades were presented maps, theoretical $[3,12]$ or experimental [2], by a number of authors. The experimental maps, although more accurate, can be applied only to the specific range of experimental parameters, defined by the researcher. The theoretical ones have the advantage of not being limited by experimental parameters. Another approach to the flow regime investigation is the CFD simulation [1], [8]. However this method promises more accurate qualitative and quantitative, internal flow description, it is time-consuming and for the complex geometries can become expensive. 
The motivation for this work is an insufficient number of relevant studies dealing with the comparison of the OIL and the OIG effervescent atomizer configurations. Our previous studies indicate the significant influence of the fluids mixing principle on the internal flows and consequently on the spray quality [9]. Therefore, we want to focus on this aspect of the IM-TFA work and study it deeply.

The objective of this work is to compare the spraying abilities of the two effervescent atomizer configurations (Fig. 1): "outside in gas" (OIG) and "outside in liquid" (OIL). The first one configuration is characteristic by the injection of the pressurized gas into the slowly flowing working liquid by the aerator holes placed on the mixing chamber wall. The OIL configuration differs by switching the liquid and the air inlets. The air is introduced into the mixing chamber from the top and the liquid is injected by the series of injectors in the mixing chamber wall.

The comparison was based on the internal and the external flow characteristics. The internal flow was investigated analytically. The online two-phase flows calculator based on the modified Baker's map (http://www.energetickeforum.cz/ext/2pf/maps/) was applied and the results were compared with the CFD results. The comparison of the external flows was based on the qualitative analysis of the spray morphology and the quantitative analysis of the droplet sizes and spray cone angle. All the external flow characteristics were explained by their relation to the internal flow.

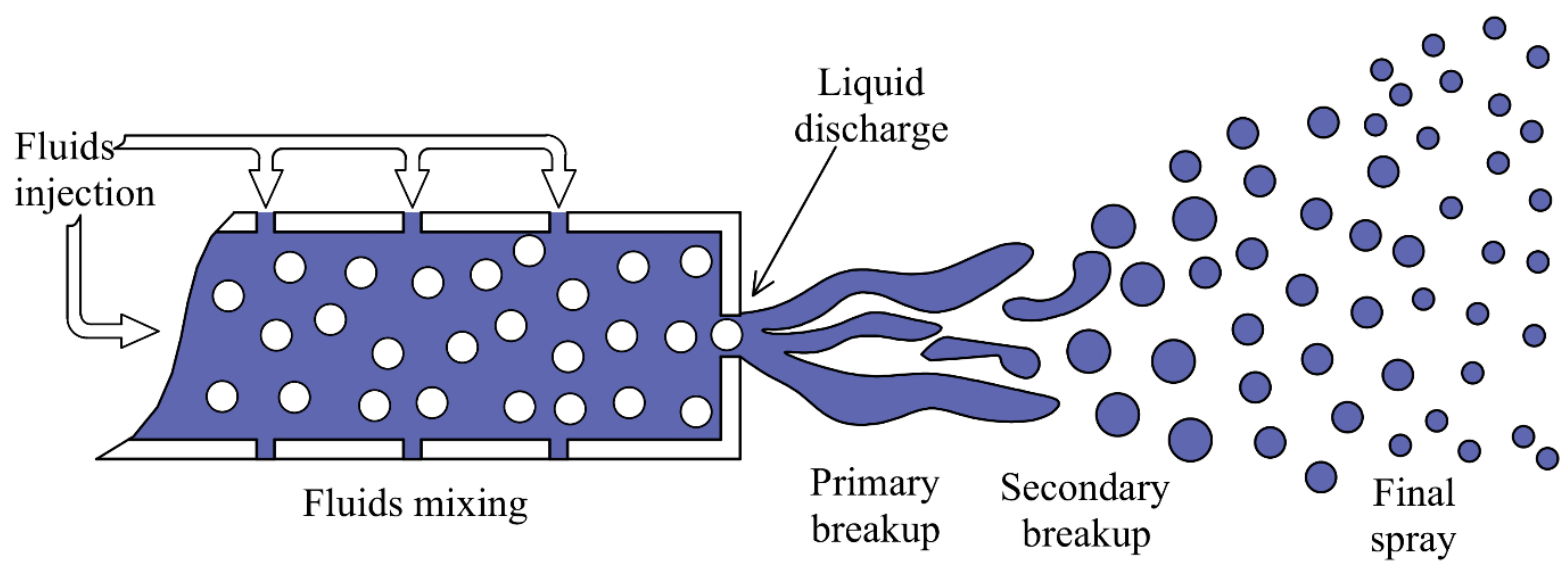

Fig. 1 Liquid atomization by the effervescent atomizer.

\section{$2 \quad$ CFD model}

The 3-D simulation was performed by a commercial CFD code ANSYS Fluent. The mixing chamber axial symmetry was used to reduce the full model into the $1 / 4$ section. The mesh element edge length varied from $200 \mu \mathrm{m}$ at the mixing chamber wall to $350 \mu \mathrm{m}$ near the geometry axis. The mesh was also smoothed in the injectors and discharge regions up to the edge length $10 \mu \mathrm{m}$.

The pressure-based SIMPLE solver (Semi-Implicit Methods Pressure Linked Equations) was used for the transient simulation with the time step length $0.1 \mathrm{~s}$ and 20 iterations per time step. However were the internal flows characteristic by the low velocities (typically $10^{-1} \mathrm{~m} / \mathrm{s}$ ) and therefore most probably laminar $\left(\operatorname{Re} \sim 10^{2}\right)$, the laminar model could not have been applied due to the compatibility issues with the used Volume of Fluid (VOF) multiphase model. Instead of the laminar, the simple two-equation k- $\varepsilon$ turbulence model, fully compatible with the VOF approach was used. 
As the flow in the mixing chamber was characteristic by the low velocity and therefore low friction pressure loss, both the fluids were considered to be incompressible. This approach is valid as far as the high-velocity liquid discharge and gas expansion is not the investigated phenomenon.

The mass flow boundary conditions were used for the fluids injectors (side and top). Values of the mass flows can be seen in Table 1. The pressure outlet (atmospheric pressure) was defined at the discharge orifice. The rest of the boundary conditions were the adiabatic walls or the symmetry planes respectively Fig. 6.

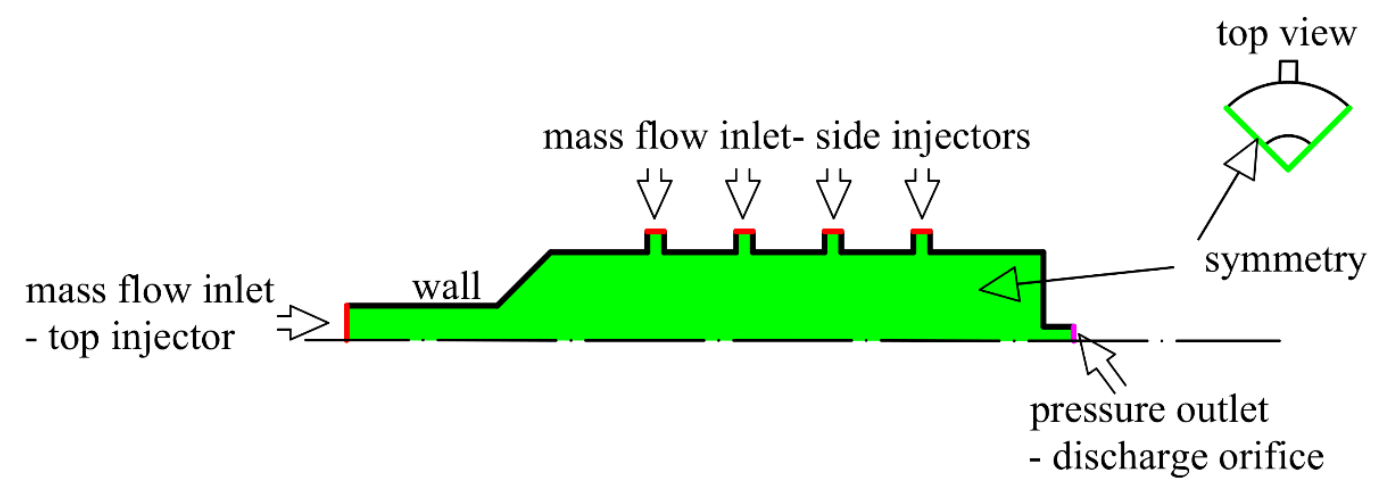

Fig. 2 Mixing chamber geometry and boundary conditions.

Table 1 Liquid mass-flows $[\mathrm{kg} / \mathrm{h}]$ for the investigated working regimes.

\begin{tabular}{|c|c|c|c|c|}
\hline GLR [\%] & 2.5 & 5 & 10 & 20 \\
\hline OIG & 3.560 & 3.50 & 2.370 & 1.30 \\
\hline OIL & 3.910 & 3.790 & 2.730 & 1.420 \\
\hline
\end{tabular}

\section{$3 \quad$ Experiment}

The experiments were performed on test rig drew on Fig. 3. An eccentric screw pump (2NL 20A, Erich Netzsch GmbH \& CO. Holding KG, Selb, Germany) was used to pump the maltodextrin solution. As the flow rate of the pump, operated at constant rotation speed, was too high for feeding our spraying devices, the redundant liquid was returned back to the reservoir by the bypass line. The precise volume flow rate towards the atomizer was adjusted using a needle valve and measured by a flow meter (PAXI, VSE GmbH, Neuenrande, Germany). To provide the atomizer with atomization gas, compressed air from a house supply was used and adjusted by a pressure reducing valve. The gas pressure was measured by a pressure gauge shortly upstream of the atomizer and its mass-flow was regulated and measured by a thermal gas mass flow controller (High-Tech EL-Flow, Bronkhorst Mättig GmbH, Kamen, Germany).

The working regimes of the atomizers were defined by constant air inlet pressure $\left(\mathrm{p}_{\mathrm{in}}=0.14 \mathrm{MPa}\right)$ and gas to liquid mass flow ratio $(\mathrm{GLR}=2.5$ and $20 \%)$. The aqueous maltodextrin solution of viscosity $\mu=60 \mathrm{mPa} \cdot \mathrm{s}$ was used as the model liquid. 


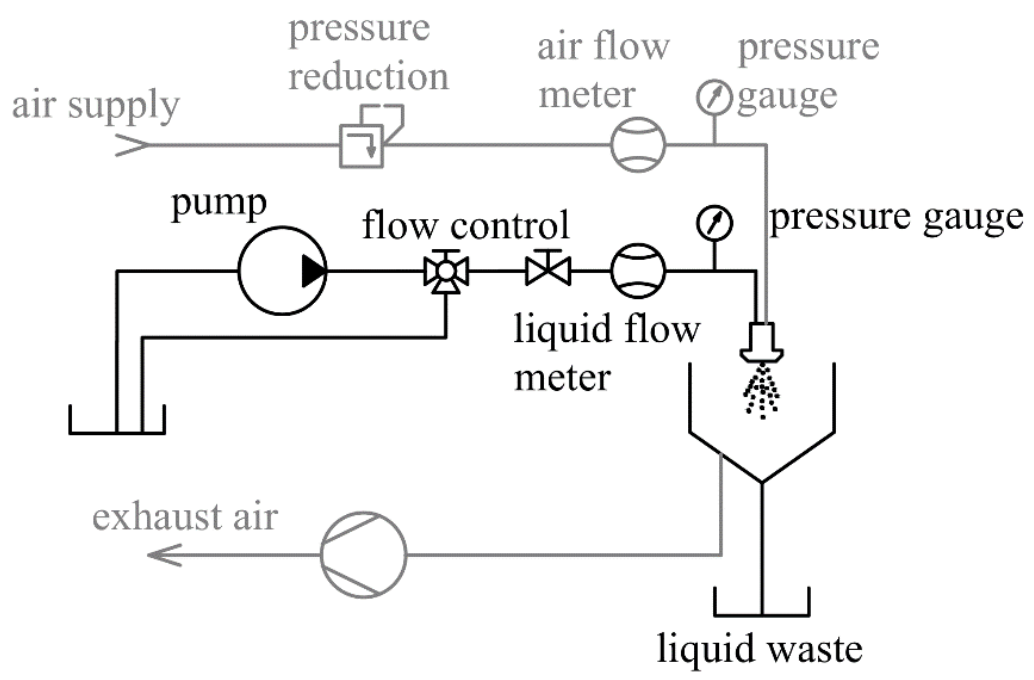

Fig. 3 Test rig

The external flow characteristics were measured by two experimental methods - the visualization and droplet sizing.

The visualization was performed by an apparatus consisted of the Pentax K-r DLSR camera equipped with a sigma 70/300 mm f/4-5.6 DG lens. The focal length was set to $200 \mathrm{~mm}$, aperture number was 5.6 an exposition time was $1 / 320 \mathrm{sec}$. The camera was arranged at the sufficient distance from the nozzle to observe the spray up to distance $100 \mathrm{~mm}$ downstream the discharge orifice. The spray was visualized by a light scattering method, therefore, the illumination (continual LED light) was placed out of the visible region under the lens axis and only refracted light was captured (Fig. 4). The captured images were processed to enhance details and make a further analysis easier. The contrast was enhanced to intensify the spray details for the qualitative spray morphology analysis (Fig. 6). This was done by the manipulation with a histogram. The spray cone edges were visualized by an intensity levels thresholding. The whole brightness range was divided equally into the 6 zones with the constant intensity value. The zone with the zero intensity (black) on the resultant images was then considered as the background while the spray was figured by the gray zones (Fig. 7). This operation allowed exact spray cone angle measurements.

The spray droplet sizes were measured with a laser diffraction spectrometer (Spraytec), $100 \mathrm{~mm}$ downstream the discharge orifice. The data acquisition rate was set to $500 \mathrm{~Hz}$ with the measurement length $25 \mathrm{sec}$, leading to a record of the 12,500 time-discrete spray drop size distributions. The Sauter mean diameter (SMD) was chosen as the representative droplet size parameter and it was calculated as the time-averaged value of the instantaneous measurements.

\section{Results}

In this section, we want to provide an analysis of our numerical and experimental results. The order of presented results will follow the stages of atomization by IM-TFA - internal flow analysis, liquid discharge and breakup, final spray, and its morphology. 


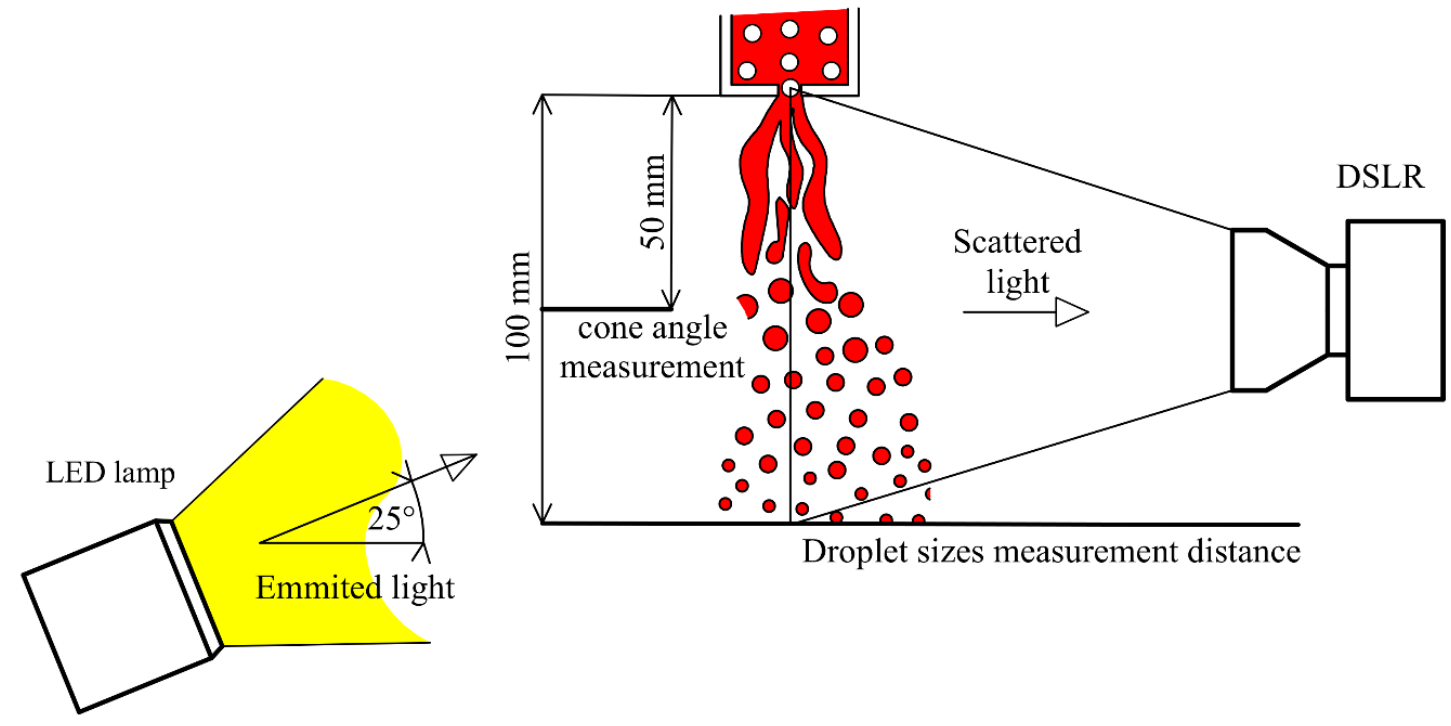

Fig. 4 Measurement of the external flow parameters.

\subsection{Internal flows}

The CFD analysis results (Fig. 5) suggest that the internal flow patterns differ for the two configurations of the effervescent atomizer and corresponding GLRs.

The internal flows of the OIG atomizer varied accordingly to the GLR change. For the low GLRs were in the mixing chamber present the air structures (slugs) divided by thin liquid films moving towards the discharge orifice. The liquid and the gas streams were not fully separated and the flow pattern was characteristic by the temporal variations of the phase distribution. The flow pattern at GLR $\geq 5 \%$ was different. The slugs were no more present and the gas created large bubbles, elongated in an axial direction up to the discharge orifice. The liquid flowed attached to the wall between the gas structures. The streams joined at the end of the mixing chamber at the orifice plate and created annular flow in the discharge orifice.

These results for the lower GLRs confirmed the analytical predictions (Table 2). Both, the Baker's map and the CFD, predicted for the OIG atomizer plug/slug flows at GLR $=2.5$ and 5\%. These regimes were also characterized by the spray cone pulsations, caused by the temporal variations of void fraction in the discharge orifice as the bubbles and the liquid fragments passed through. These temporal void fraction variations were previously experimentally related to the plug and the slug flows in the mixing chamber [7] and therefore our CFD results provide a satisfactory explanation of the spray pulsations origin.

The agreement was also found in the stable spray, generated at GLR $\geq 10 \%$ and the stable internal flow structure estimated by CFD, while the analytical approach failed to provide satisfactory internal flow description.

The different mixing principle of the OIL atomizer caused the significant difference in the internal flow pattern, even when it worked under the same conditions. Regardless to the GLR was the liquid attached to the wall and it flowed towards the end of the mixing chamber and the discharge orifice. The rest of the mixing chamber volume was occupied by the atomizing gas. The only qualitative difference amongst the observed flows was the thickness of the liquid stream for different GLRs. For this device estimated the Baker's map the same internal flow patterns as for the previous atomizer (Table 2) and the CFD results did not match this 
prediction for any of the working regimes. We can state, that the experiments confirmed the CFD results. The spray was stable for almost all the investigated regimes which accord to the estimated flow pattern with the wall attached liquid flow without plugs or slugs. The only pulsations were experimentally observed for the GLR $=2.5 \%$ and their origin was not clearly explained by the CFD analysis.

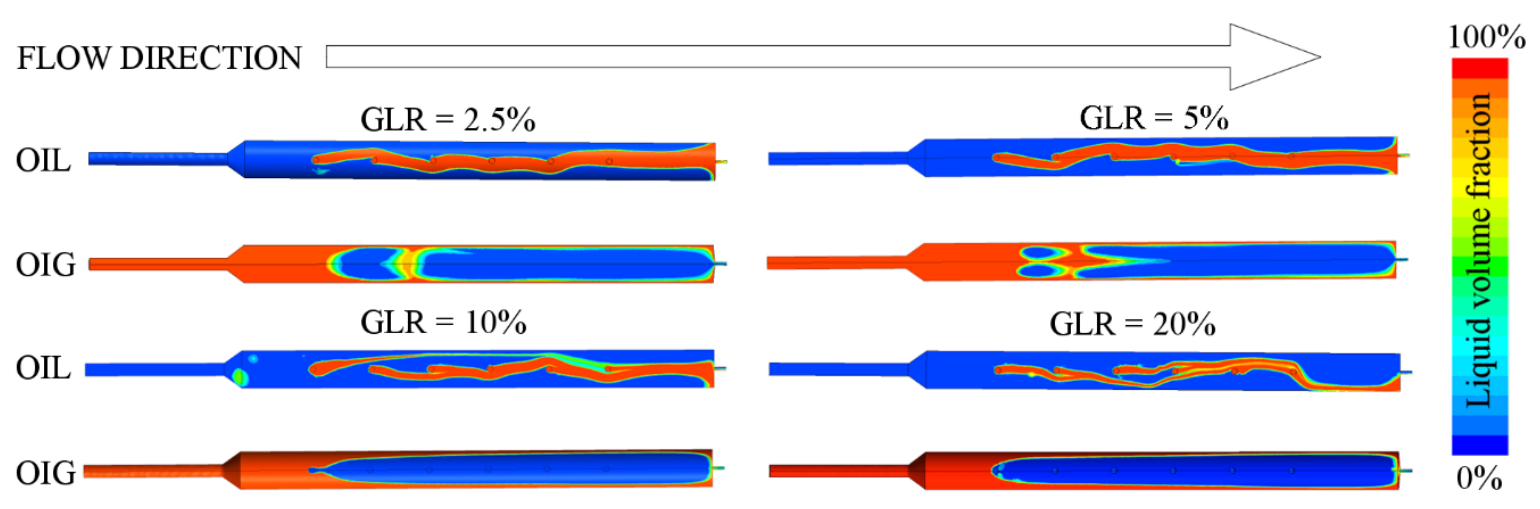

Fig. 5 Internal flows patterns estimated by CFD.

Table 2 Comparison of the internal flows estimation by the Baker's map and the CFD for different GLR.

\begin{tabular}{|c|c|c|c|c|c|}
\cline { 3 - 6 } \multicolumn{2}{c|}{} & $2.5 \%$ & $5 \%$ & $10 \%$ & $20 \%$ \\
\hline \multirow{2}{*}{$\begin{array}{c}\text { Baker's } \\
\text { map }\end{array}$} & OIG & Plug/Slug & Plug/Slug & Slug & Slug \\
\cline { 2 - 6 } & OIL & Plug/Slug & Plug/Slug & Slug & Slug \\
\hline \multirow{2}{*}{$\begin{array}{c}\text { CFD } \\
\text { results }\end{array}$} & OIG & Slug & Slug & Annular & Annular \\
\cline { 2 - 6 } & OIL & Annular & Annular & Annular & Annular \\
\hline
\end{tabular}

\subsection{Spray morphology and quality}

The single images taken by the DSLR camera were used for qualitative analysis of the spray morphology. Fig. 6 shows spray patterns, generated for the each studied operating regime, whereby the first row of images shows the spray generated by the OIG atomizer and the bottom row shows is for the OIL device.

At the GLR $=2.5 \%$ were both the devices characteristic by producing a spray with the liquid concentrated in the large structures, close to the cone axis. The products of secondary breakup - the small droplets - were not present in the spray pattern up to the distance $20 \mathrm{~mm}$ downstream the discharge orifice. From this point, the number of small droplets increased while the number of ligaments in central liquid core decreased. The difference between the sprays is visible at a further distance from the discharge orifice where the liquid core almost disappeared for the OIL atomizer while it was present for the OIG device. The droplet sizes measurements confirmed the qualitative observations - the averaged SMD was significantly smaller for the OIL atomizer (Fig. 6). This difference in the spray quality had an origin in the internal flows. The annular film, created in the discharge orifice of the OIL atomizer, crumbled into the droplets of the diameter smaller than the discharge orifice. The different situation was observed for the OIG device. The temporal void fraction variations described in the previous section caused the creation of the ligaments of the size comparable to the discharge orifice diameter. Due to the small amount of the expanding atomizing gas in the 
near-nozzle region was the energy available for the atomization low. The large liquid structures were therefore not atomized properly.

At the GLR $=5 \%$ were the small droplets for both the atomizers observed just after the discharge orifice. The spray pattern of the OIG atomizer is up to distance $50 \mathrm{~mm}$ characteristic by the presence of the large structures (large droplets were faster and created motion blur-stripes - on images) while the second atomizer produced the spray with the considerably larger amount of the small liquid fragments. Also, the final spray quality (in terms of SMD) was better for the OIL atomizer. The difference of the atomization process for the two atomizer configurations is the same as for the previous working regime. However, the higher amount of the expanding atomizing gas and consequently more energy available for the atomization led to the better liquid breakup and therefore significant SMD decrease for both the devices.

At the GLR $\geq 5 \%$ was the spray pattern for both the atomizers similar. It consisted mostly from the small droplets. These regimes were typical by the wall-attached internal liquid flows for both the devices. Therefore, the flows in the discharge orifices were most probably annular and therefore the measured droplet sizes were much smaller that the discharge orifice diameter. The decrease of the SMD with the GLR increase from 10 to $20 \%$ was caused by the increase of the available potential energy carried by the high mass flow of the pressurized gas. 


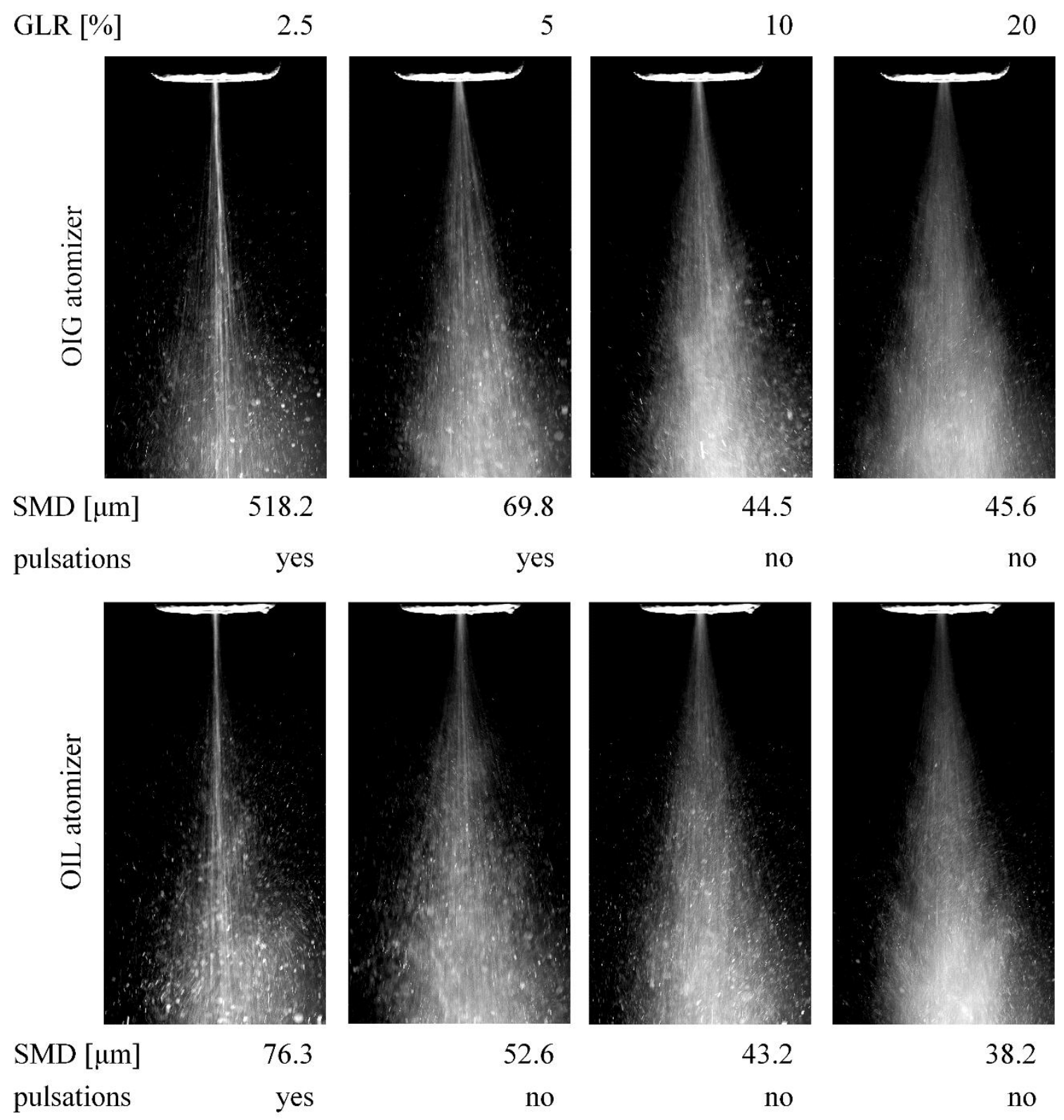

Fig. 6 Spray images with adjusted contrast.

\subsection{Spray cone angle}

The measurement of the spray cone angle was performed on the images processed by intensity levels thresholding. However, the original spray photos (Fig. 6) can be used to measure the spray cone angle, the recognition of the cone borders is subjective. In the adjusted images (Fig. 7) is the spray edge exactly defined by a transition from the black background to the gray color.

The spray cone angle of the OIG atomizer increased rapidly from 11 to 18 degrees with the GLR increase from 2.5 to $5 \%$. The further spray cone angle increase was less intensive $\left(+3^{\circ}\right.$ for GLR $=10 \%$ ) or negligible for the regime defined by the highest GLR.

The measured spray cone angle for the OIL atomizer at the lower GLRs was considerably larger-16 and 22 degrees for the GLR $=2.5$ and 5\% respectively. The change of the spray cone angle for higher GLRs was negligible. 
The difference of the spray cone angle for the low GLRs was given by the above-described factors affecting the spray morphology. The breakup of the annular liquid film in the case of the OIL atomizer produced smaller droplets which were carried in the radial direction by the expanding gas more easily than the large liquid fragments created by the OIG atomizer. When the annular liquid film was formed in the discharge orifice of the OIG atomizer at GLRs $\geq 10 \%$ both the atomizers produced the spray with the comparable droplet sizes and therefore the expanding gas formed the sprays with nearly-identical cone angles.

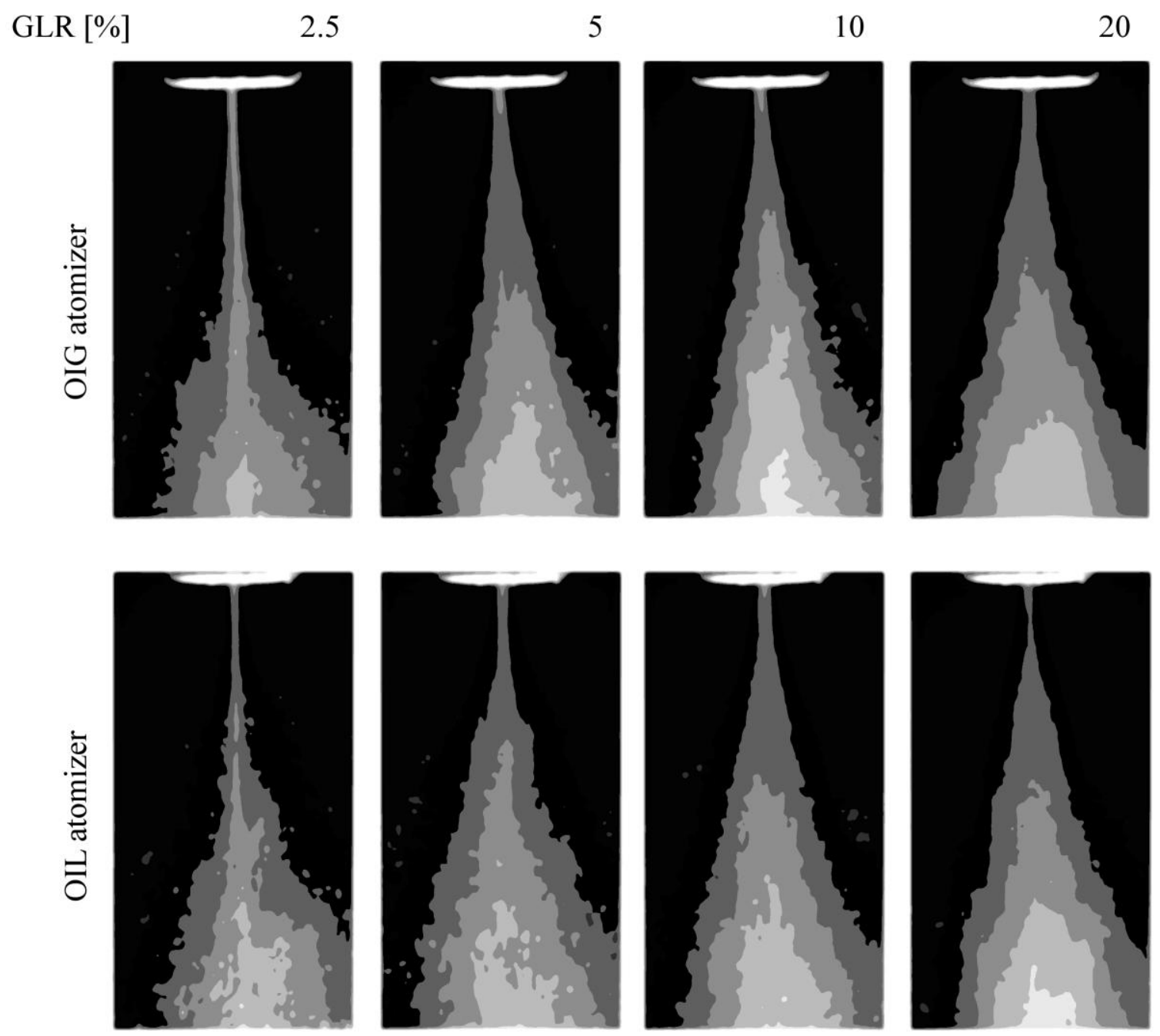

Fig. 7 Spray cone images after intensity level thresholding. 


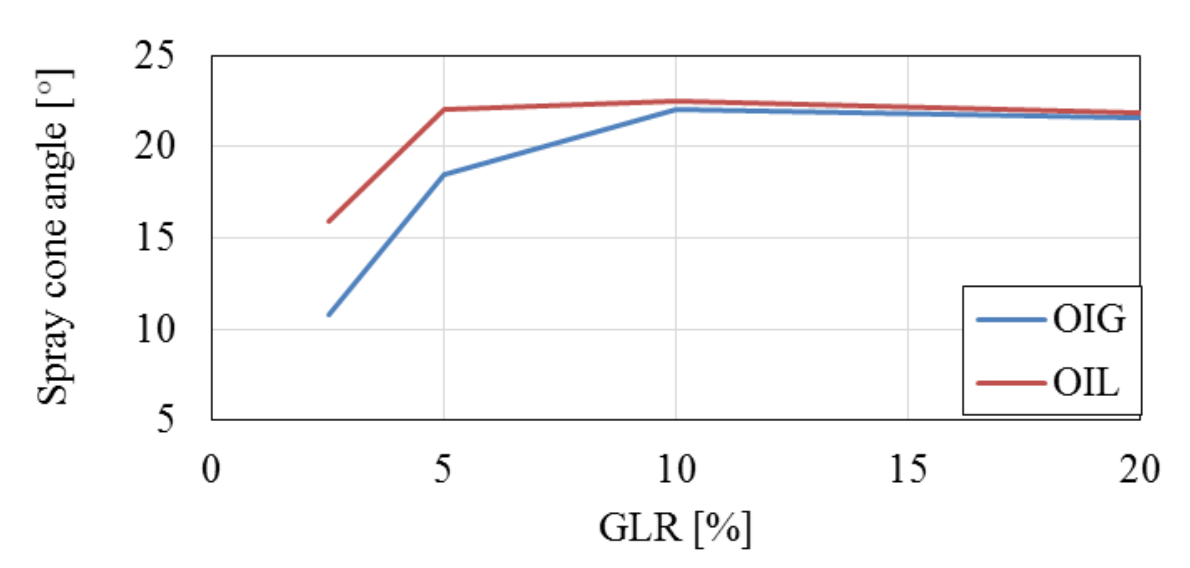

Fig. 8 Measured spray cone angles.

\section{CONCLUSION}

In this work, we presented the results of our recent research of the twin internal mixing twin-fluid atomizers. We studied the influence of the fluid injection configuration on the internal flows and external sprays parameters. The internal flows were investigated numerically and the external flows experimentally. We spray the viscous aqueous maltodextrin solutions at a constant inlet pressure of gas. The atomizers working regime was defined by the GLR within the range 2.5 to $20 \%$.

Our findings can be shortly concluded in the following points:

- The internal flow patterns are formed not only by the working parameters and fluids properties as was predicted by the two-phase flow map. The mixing principle (outside-in-gas, outside-in-liquid) has a crucial influence on the internal flows. The annular flow in the discharge orifice can be achieved even for the low GLRs when OIL atomizer is used because the liquid injection at low velocities causes the wallattached liquid flow in the mixing chamber.

- The spray morphology, quality, and the cone angle are significantly influenced by the internal flows. For the regimes of the OIG atomizer characteristic by the slug flows (GLR $=2.5$ and $5 \%$ ) were the sprays characteristic by pulsations, production of large liquid fragments and low cone angle. This was caused by the temporal void fraction variation in the discharge orifice leading to the production thick ligaments instead of the thin annular film during the discharge. The thin ligaments were not atomized properly as the low amount of the atomizing gas did not contain sufficient amount of the energy for atomization. Consequently were the large liquid fragments not carried in the radial direction which led to the narrow spray cone.

- The OIL atomizer was characteristic by the wall-attached internal flow and therefore annular flow in the discharge orifice even at the low GLRs. The breakup of the annular film led to the small droplet diameters. The small droplets were carried by the expanding gas in the radial direction, which increased the spray cone angle.

- The overall performance of the OIL atomizer was at low GLRs better than for the OIG configuration.

- The internal flows estimated by the CFD simulations were similar for the higher GLRs, therefore, were the sprays characteristics of both the atomizing devices comparable. 


\section{ACKNOWLEDGEMENT}

The authors also appreciate support from Prof. Dr.-Ing. Heike P. Schuchmann, Dr. rer. nat. Dipl.-Ing. Volker Gaukel and Dipl.-Ing Philipp Stähle from Karlsruhe Institute of Technology for providing us their test rig for experiments and other support and cooperation. We want to also appreciate the help from doc. Ing. Jan Jedelsky, PhD from Brno University of Technology for providing his atomizers geometry details.

\section{References}

[1] ABDULKADIR, M., HERNANDEZ-PEREZ, V., LO, S., LOWNDES, I.S., AZZOPARDI, B.J.: Comparison of experimental and Computational Fluid Dynamics (CFD) studies of slug flow in a vertical riser, Experimental Thermal and Fluid Science, Volume 68, November 2015, pp. 468-483, ISSN 0894-1777

[2] BAKER, O.: Simultaneous flow of oil and gas, Oil Gas J., 53, 1954, pp. 185-195

[3] BARNEA, D.: A unified model for predicting flow-pattern transitions for the whole range of pipe inclinations, Int. J. Multiphase Flow, 13, 1987

[4] BUCKNER, H.N., SOJKA P.E.: Effervescent atomization of high-viscosity fluids. Part 1: Newtonian liquids, Atomization Sprays, 1, 1991, pp. 239-252

[5] FERREIRA G., GARCÍA J.A., BARRERAS F., LOZANO A., LINCHETA E.: Design optimization of twin-fluid atomizers with an internal mixing chamber for heavy fuel oils, Fuel Process. Technol., 90, 2009, pp. 270-278

[6] JEDELSKY J., JICHA M.: Energy conversion during effervescent atomization, Fuel, Volume 111, September 2013, Pages 836-844, ISSN 0016-2361

[7] LORCHER, M., SCHMIDT, F., MEWES, D.: Flow field and phase distribution inside effervescent atomizers. In: 9th ICLASS 2003, 2003, pp. 12-9.

[8] MANDAL, A., JOG, M.A., XUE, J., IBRAHIM, A.A.: Flow of power-law fluids in simplex atomizers, International Journal of Heat and Fluid Flow, Volume 29, Issue 5, October 2008, pp. 1494-1503, ISSN 0142-727X

[9] MLKVIK, M., STÄHLE, P., SCHUCHMANN, H. P., GAUKEL, V., JEDELSKY, J., JICHA, M.: Twin-fluid atomization of viscous liquids: The effect of atomizer construction on breakup process, spray stability and droplet size. International Journal of Multiphase Flow, 77, 2015, pp. 19-31

[10] SCHRÖDER J., KRAUS S., ROCHA B.B., GAUKEL V., SCHUCHMANN H.P.: Characterization of gelatinized corn starch suspensions and resulting drop size distributions after effervescent atomization, J. Food Eng., 105, 2011, pp. 656-662

[11] STÄHLE, P., GAUKEL, V., SCHUCHMANN, H.P.: Influence of mixing chamber length and liquid viscosity on the effervescent atomization of maltodextrin solutions. In: ILASS - Europe, 2013, Chania, Greece

[12] GOGA V., HUČKO B.: Phenomenological Material Model of Foam Solids. In Journal of Mechanical Engineering - Strojnicky časopis, Vol. 65, No. 1, 2015, pp.5-20, ISSN 0039-2472 
